\title{
Marine turtle hatchlings use multiple sensory cues to orient their crawling towards the sea: biological and conservation policy implications
}

\author{
Alma Lilia Fuentes-Farias ${ }^{1 *}$, Gabriel Gutiérrez-Ospina², Esperanza Meléndez Herrera ${ }^{1}$, Verónica Ca- \\ marena-Ramírez $^{1 \#}$, Gerardo Ochoa-Tovar ${ }^{1 \#}$, Julieta Mendoza-Torreblanca ${ }^{2 \S}$, Armida Báez-Saldaña ${ }^{2}$, \\ Raquel Martínez-Méndez $^{2 \#}$, Jaime Urrutia-Fucugauchi ${ }^{3}$, María Luisa García Zepeda ${ }^{4}$

\footnotetext{
${ }^{1}$ Laboratorio de Ecofisiología, Facultad de Biología, Universidad Michoacana de San Nicolás de Hidalgo, Ciudad Universitaria, Morelia Michoacán, México, 58230;

${ }^{2}$ Laboratorio de Biología de Sistemas, Instituto de Investigaciones Biomédicas, Universidad Nacional Autónoma de México, Ciudad Universitaria, México D.F., 04510;

${ }^{3}$ Laboratorio de Paleomagnetismo, Instituto de Geofísica, Universidad Nacional Autónoma de México, Ciudad Universitaria, México D.F., 04510;

${ }^{4}$ Laboratorio de Paleontología, Facultad de Biología, Universidad Michoacana de San Nicolás de Hidalgo, Ciudad Universitaria, Morelia Michoacán, México, 58230.
} \\ Email:*almafuentes70@hotmail.com
}

Received 24 December 2010; revised 7 February 2011; accepted 24 February 2011.

\begin{abstract}
The ability of sea turtle hatchlings to find the seashore soon after hatching is thought to be exclusively dependent upon visual information. Target-oriented movements in most vertebrates, however, relay on combining information gathered through different sensory systems. Hence, in this work, we investigated whether olfactory and/or magnetic information might complement visual cues during hatchling's seaward crawling. Acute olfactory deprivation and distorted magnetic sensation in visually competent hatchlings resulted in a scattering of seaward crawling routes among cardinal points, some of them being different from those strongly preferred by control hatchlings. In addition, blindfolded hatchlings also displayed a striking misrouting while crawling on the beach surface in spite of having intact olfactory and magnetic senses. Together these results support that not only visual information is crucial for seaward crawling, but also that olfactory and magnetic information complement visual cues when turtle hatchlings display this behavior. Hence, the present observations suggest that multisensory cues are used by turtle hatchlings while crawling towards the sea. This work also has important implications on the design of species conservation measures and policies. In the near
\end{abstract}

${ }^{\#}$ These authors contributed equally to the present work.

${ }^{\S}$ Actual adress: Laboratorio de Neuromorfometría, Instituto Nacional de Pediatría, México D.F., 04530. future, efforts must be made to identify and preserve the local natural sources of odors and magnetic cues, in addition to preventing the perturbing effects of artificial lighting on adult and hatchling turtle crawling behavior.

Keywords: Olfaction; Magnetoreception; Vision; Chelonia aggasizi; Seaward orientation; Reptiles; Intermodal interactions; Multisensory integration

\section{INTRODUCTION}

Hatchlings of marine turtles crawl towards the sea soon after they emerge from the nest's chamber. Because this behavior is displayed by hatchlings that have not experienced their surroundings, one might think that seaward crawling behavior is somehow imprinted in the brain's circuits before hatching. However, the observations that seaward crawling can be perturbed by exposing turtle hatchlings to bright silhouettes or horizons or to artificial lights [1-4] rule out that this behavior is "hard wired" in the hatchlings' brains. This is why numerous previous attempts have been made to identify the nature of the information used by turtle hatchlings to guide their movements while attempting to reach the sea. In this context, most studies coincide in supporting that seaward crawling heavily depends upon visual information [1-4]. Target-oriented movements in most vertebrates, nonetheless, relay on combining the information gathered through different sensory systems [5-7]. In fact, interactions among sensory modalities may improve or 
decline the ability of animals to effectively display target-oriented movements [5,6].

In this work, we investigated whether seaward crawling displayed by hatchlings of Chelonia aggasizi is influenced by olfactory or magnetic cues, since these organisms likely have both types of information readily available in their natal beaches [8,9]. The possibility of turtle hatchlings using multisensory cues to guide their movements while traveling to the sea has not been evaluated given the dominance of the view that they rely exclusively on visual information to achieve this task.

\section{MATERIAL AND METHODS}

Behavioral experiments were performed using newborn turtle hatchlings (23 - 25 grams of body weight) of the species Chelonia agassizi obtained from four different artificial nests. The specimens were collected as soon as they emerged and were transferred to a location where natural nests abounded. All of the experiments were carried out on Colola beach $\left(103^{\circ} 26^{\prime} \mathrm{W}, 18^{\circ} 18^{\prime} \mathrm{N}\right.$, Michoacán, México) between 10:00 PM and 2:00 AM. A nest was arbitrary chosen as the departure site. This site was 122 meters away from the sea shore. Before testing, hatchlings were clustered in five groups (see below), each hatchling was subjected to a single behavioral test and was released free by the end of it. Experimental groups were formed as follows:

a) The control group clustered intact hatchlings $(n=15)$.

b) Blindfolded hatchlings $(n=10)$. These specimens were rendered sightless by keeping their eyelids closed by means of Millipore adhesive patches (Figure 1(a)).

c) Olfactory deprived hatchlings $(n=14)$. These specimens were olfactory deprived by transiently obliterating the hatchlings' narins with dental wax (Figure 1(b)).

d) Magnetically distorted hatchlings. In these groups, magnetic field distortion was achieved by attaching non-permanently either $350 \mathrm{mT}(\mathrm{n}=16 ; 4.5$ grams of weight; Figure 1(c)) or $85 \mathrm{mT}$ ( $\mathrm{n}=15$; 0.04 grams of weight; Figure 1(d)) magnets on the hatchlings upper carapace or skull, respectively.

Weight loaded hatchlings. The specimens of these groups carried $0.04(\mathrm{n}=10)$ or $4.5(\mathrm{n}=10)$ gram weights made of diamagnetic material attached to their skull or carapace, as was did for the magnetically distorted hatchlings.

Once assigned to an experimental group, hatchlings were released one by one and carefully followed by the experimenter. The orientation vector was estimated by tracing a normalization line from the departure nest to the final position occupied by each hatchling on the beach surface relative to the geomagnetic north, the nest of origin and the beach front. Although control hatch

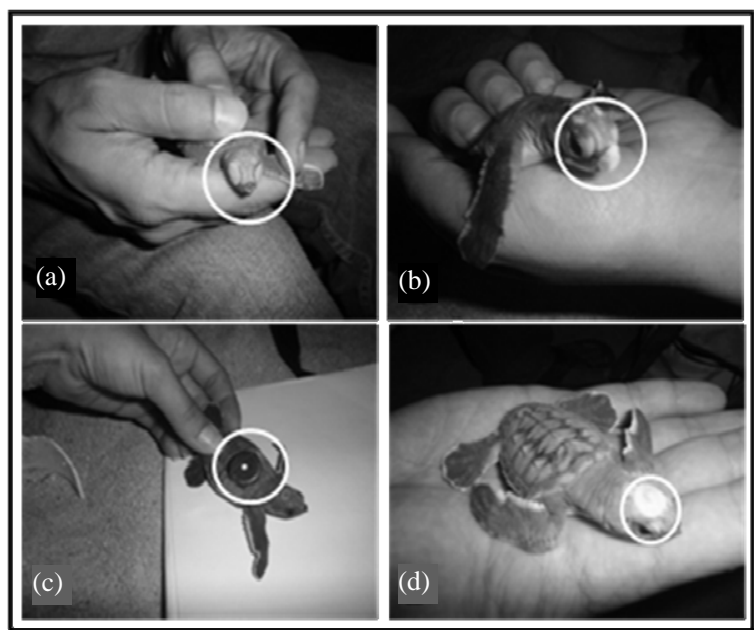

Figure 1. Photographs that illustrate the methods used to produce transient visual (a) or olfactory (b) deprivation, as well as magnetic field distortion (c and d). See text for further details.

lings reached the sea in an average time of $15.35 \pm 3.21$ minutes, many of the disoriented hatchlings assigned to other experimental groups would have never reached the sea in a time compatible with survival. In these cases, we decided to end the test after twenty minutes of having been initiated it. The final position of these disoriented hatchlings was estimated as mentioned before.

Statistical comparisons among orientation vectors of each group were carried out using Chi-square and Fisher exact tests. In all cases, the level of significance was set at $\mathrm{p}<0.01$. The experimental procedures followed the guidelines published by the National Institutes of Health Guide for the Care and Use of Laboratory Animals and were revised and approved by ethical committees at the Secretaría del Medio Ambiente y Recursos Naturales (SEMARNAT Permission No. SGPA/DGVS/10 414, 14340, 5896).

\section{RESULTS}

\subsection{Sea-Ward Crawling Behavior}

Figure 2 and Table 1 summarize the results obtained in our experimental series. In the following paragraphs, we will describe behavioral features displayed by hatchlings clustered in different experimental groups that complement the information provided graphically. In the case of control hatchlings, they found their way out of the departure nest by climbing its walls in direction to the sea. Their movements were rapid, vigorous and firm, and there was no vacillation as they advanced along the beach. They effectively avoided sand dunes and clusters of vegetation. Control hatchlings move following a near straight line from the departure nest to the sea shore running along vectors pointing predominantly to the south 


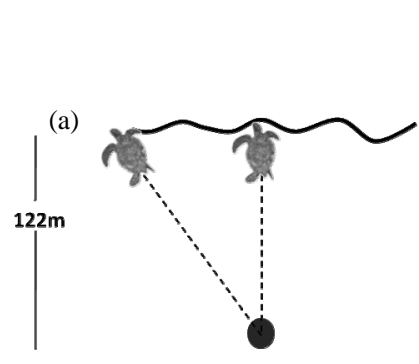

(b)
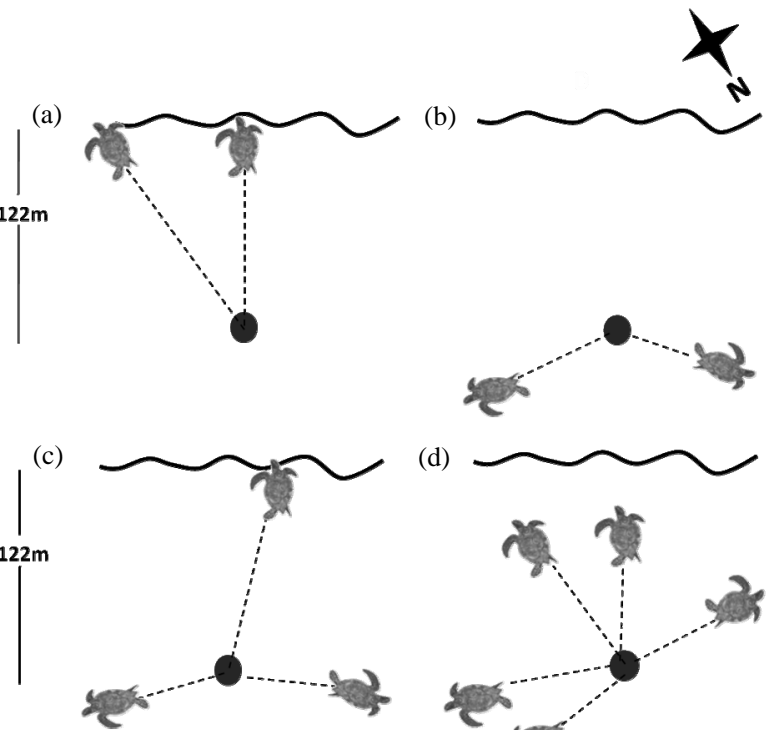

(d)
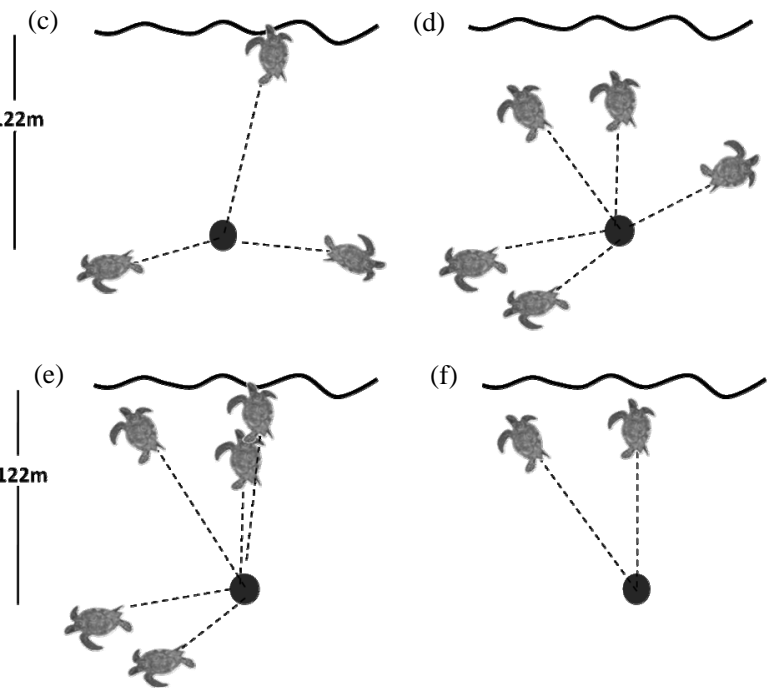

(f)

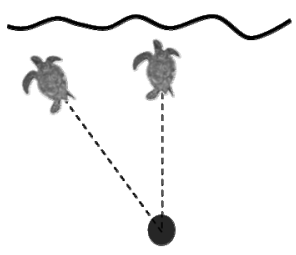

Figure 2. Schemes that represent the orientation vectors followed by turtle hatchling while crawling to the sea when undisturbed (a), subjected to visual (b) or olfactory (c) deprivation, magnetic field distortion induced by $350 \mathrm{mT}$ (d) or $85 \mathrm{mT}$ (e) magnets, or after being weight-loaded with 4.5 grams of diamagnetic material (f).

Table 1. Crawling orientation of control, blind-folded, olfactory deprived, magnetically distorted and weight-loaded hatchlings.

\begin{tabular}{|c|c|c|c|c|c|c|}
\hline \multirow[t]{2}{*}{ Group } & \multicolumn{6}{|c|}{$\begin{array}{c}\text { Orientation } \\
\text { Hatchling number }\end{array}$} \\
\hline & E & S & $\mathrm{NE}$ & W & SW & NW \\
\hline $\begin{array}{l}\text { Control } \\
\mathrm{N}=15\end{array}$ & & 14 & & & 1 & \\
\hline $\begin{array}{c}\text { Blind-folded }^{\#} \\
\mathrm{~N}=10\end{array}$ & 7 & & & & & 3 \\
\hline $\begin{array}{l}\text { Olfactory Deprivation }{ }^{\&} \\
\qquad(\mathrm{n}=14)\end{array}$ & 8 & & & & 4 & 2 \\
\hline $\begin{array}{l}\text { Magnetic Distortion } \\
\quad(85 \mathrm{mT} ; \mathrm{n}=15)\end{array}$ & 2 & 6 & 3 & & 4 & \\
\hline $\begin{array}{c}\text { Weight-loaded } \\
(0.04 \text { grams; } n=10)\end{array}$ & & 3 & & & 7 & \\
\hline $\begin{array}{l}\text { Magnetic Distortion* } \\
\quad(350 \mathrm{mT} ; \mathrm{n}=16)\end{array}$ & 5 & 2 & 1 & 7 & 1 & \\
\hline $\begin{array}{c}\text { Weight-loaded } \\
(4.5 \text { grams; } n=10)\end{array}$ & & 4 & & & 6 & \\
\hline
\end{tabular}

or southwest (Figure 2(a)). In contrast, blindfolded hatchlings displayed no seaward orientation whatsoever right from the beginning of the behavioral test. Once placed in the departure nest, they moved in circles following the nest's circumference for several minutes. Although their trajectories were highly erratic, their movements were always rapid and firm. Once out of the nest, hatchlings of this group moved in opposite directions to the sea following vectors oriented east or northwest. They never avoided sand dunes and/or vegetation covers. As a result, none of the visually deprived hatchlings reach the seashore (Figure 2(b)). Olfactory deprived hatchlings appeared confused right from the outset. These hatchlings, however, started crawling immediately after they were placed in the departure nest. Although their movements were firm and rapid, seaward crawling appeared erratic and hesitant at all times. Once out of the nest, the paths they followed were tortuous and frequently encountered and traversed sand dunes and vegetation clumps. Olfactory deprived hatchlings move along vectors oriented east, southwest or northwest; only those heading to the southwest $(n=4 / 14)$ reached the sea. (Figure 2(c)). Hatchlings carrying $350 \mathrm{mT}$ magnets showed difficulties in finding their way out of the nest. They travel in circles inside the nest during several minutes after which they ascended following tortuous paths that frequently pointed against the sea. Once out of the nest, these hatchlings move in bursts of motor activity. They stopped their locomotor activity frequently. When crawling resumed, hatchlings always displayed vigorous, rapid and firm movements. The orientation vector varied greatly among these hatchlings pointing east, south, northeast, west and southwest (Figure 2(d)), none of these animals reached the sea within the time window defined for the test to be accomplished. Hatchlings carrying $85 \mathrm{mT}$ magnets initiated seaward crawling as soon as they were placed in the departure nest. They found their way out from it climbing its walls following straight paths that pointed to the sea. Once out of the departure nest, these hatchlings displayed vigorous, firm and rapid movements. Although they move continuously, they switched directions frequently while traversing the beach. As a result, the orientation vectors also varied among these hatchling pointing east, south, northeast and southwest (Figure 2(e)), only those heading to the south $(n=6 / 15)$ or some of them heading to the southwest $(n=2 / 15)$ reached the sea. Hatchlings loaded with 4.5 grams always headed towards the south or southwest (Figure 2(f)), none of these animals reached the sea within the time window defined for the test to be accomplished. Their movements were similar to those seen in control hatchlings. However, they stopped frequently as they crawl to the sea. Finally, 0.04 grams weight-loaded hatchlings headed towards the south or southwest; those orienting to the south and only three of those oriented to the southwest reached the sea (not shown). 


\section{DISCUSSION}

Previous studies support that the visual scenery provides cues for marine turtle hatchlings to orient their crawling towards the sea [1-4]. The profound disorientation observed in blindfolded hatchlings, in the presence of intact olfactory and magnetosensory senses, confirms this conception. Our results, however, support that olfactory and magnetic cues also are used by marine turtle hatchlings to define their seaward crawling routes. This conclusion is supported by the finding that olfactory deprivation or magnetic field distortion rendered most hatchlings disoriented even though they are visually competent. It is this very set of observations what supports that multisensory cues are used by, and that multisensory integration is taking place in, turtle hatchlings while crawling towards the sea. The fact that they cannot compensate immediately the acute, transient lack of a sensory modality must not be surprising because sensory compensation responses normally take place after hours, days or even weeks following deprivation [10].

An interesting observation is that most of the hatchlings exposed to $350 \mathrm{mT}$ magnets attached to their carapaces crawled following inadequate orientation routs. In this group, none of the hatchlings reached the sea. Although it can be argued that weight-loading could have prevented them to orient correctly and accomplish their goal within the time frame set, clearly overweight was not the cause of disorientation since hatchlings carrying similar weights made of diamagnetic materials also failed to reach the sea, but always crawled following correct directions.

Another important observation is that $85 \mathrm{mT}$ magnets rendered turtles less disoriented than $350 \mathrm{mT}$ magnets. This may signify that the magnetoceptive system in turtle hatchlings has a dynamic range of functioning (i.e., discrimination threshold), as it must be expected for a sensory system.

Previous behavioral data have led to the conclusion that sea turtle hatchlings rely on magnetic information to orient their navigation only until they reach the ocean $[11,12]$. Our results support, nonetheless, that the ability of perceiving magnetic information is already in place by the time of hatching and that magnetic information is also used by hatchlings to complement visual and olfactory cues to orient their movements on the beach in their way to the sea. This result is not unexpected because turtles are highly precocial species that provide no parental care to their offspring, so hatchlings must be ready to cope with the environmental challenges as soon as they hatch.

A final note that bears on the verge of conservation measures and policies must be made. Previous work has suggested that artificial lightning might provide disori- enting or confounding cues to adult turtles or their hatchlings while crawling on the beach. So, it is recommendable to dictate norms aimed at preventing as much as possible the occurrence of this disturbing element near turtle natal beaches. In contrast, nothing has been said about potential harms that human developments could impose on olfactory and magnetic ambient cues. A recent geophysical survey carried out by our group supports that Colola beach provides magnetic cues that might be useful for turtles to perform beach identification, magnetic imprinting and nest-site selection $[8,9]$. Because some of the natural sources of magnetic cues are not located within the protected limits of Colola beach, our behavioral study calls for the relocation of the boundaries of this natural reserve.

\section{ACKNOWLEDGEMENTS}

Authors thank to Luz Lilia Jiménez Rico, Patricia Padilla Cortés, Jesus Ramirez Santos, Martha Carrasco Fuentes y Raymundo Reyes for technical and administrative assistance. We are also indebted to Angel Ontiveros Aquino and his crew for providing the conditions necessary to collect the black turtle specimens and to carry out the field experiments. This work was supported by grants from the Consejo Nacional de Ciencia y Tecnología (CONACyT No.45872M, 94312 and 82879 to GGO) and from the Coordinación de la Investigación Científica, Universidad Michoacana de San Nicolás de Hidalgo (No.8.37 to ALFF). Additional funding was provided by the Coordinación de la Investigación Científica, Universidad Nacional Autónoma de México, and PROMEP, SEP. The work described in the paper was authorized by SEMARNAT (Permissions No. SGPA/DGVS/10 414, 14340, 5896)

\section{REFERENCES}

[1] Salmon, M., Wyneken, J. and Lucas, M. (1992) Seafinding by Hatchling sea turtles: Role of brightness, silhouette and beach slope as orientation cue. Behaviour, 122, 56-77. doi:10.1163/156853992X00309

[2] Ehrenfeld, D.W. and Carr, A. (1967) The role of vision in the sea-finding orientation of the green turtle Cheloniamydas. Animal Behavior, 15, 25-36. doi:10.1016/S0003-3472(67)80007-1

[3] Salmon, M., Garro, M., Pender, D., Goff, M. and Reiners, R. (1995) Behavior of loggerhead sea turtles on an urban beach. Journal of Herpetology, 29, 568-576. doi:10.2307/1564740

[4] Tuxbury, S.M. and Salmon, M. (2005) Competitive interactions between artificial lighting and natural cues during seafinding by hatchling marine turtles. Biological Conservation, 121, 311-316. doi:10.1016/j.biocon.2004.04.022

[5] Calvert, G.A., Spence, C. and Stein, B.E. (2004) The handbook of multisensory processes. MIT Press, Cambridge.

[6] Stein, B.E. and Meredith, M.A. (1993) The merging of the senses. MIT Press, Cambridge.

[7] Walcot, C. (2005) Multi-modal orientation cues in hom- 
ing pigeons. Integrative and Comparative Biology, 45, 574-581. doi:10.1093/icb/45.3.574

[8] Fuentes-Farías, A.L., Urrutia-Fucugauchi, J., Gutiérrez-Ospina, G., Pérez-Cruz, L. and Garduño-Monroy, V.H. (2008) Magnetic features of marine black turtle natal beaches and implications for nest selection. Geofísica Internacional, 47, 311-318.

[9] Fuentes-Farías, A.L., Garduño-Monroy, V.H., Gutiérrez-Ospina, G., Pérez-Cruz, L., Meléndez-Herrera, E. amd Urrutia-Fucugauchi J. (2010) Reconnaissance study of marine turtle nesting beaches of Colola and Maruata, Michoacán Coast, southern México. Geofísica Interna- cional, 49, 201-212.

[10] Lewald, J. (2007) More accurate sound localization induced by short-term light deprivation. Neuropsychologia, 45, 1215-1222.

doi:10.1016/j.neuropsychologia.2006.10.006

[11] Goff, M., Salmon, M. and Lohmann, K.J. (1998) Hatchling sea turtles use surface waves to establish a magnetic compass direction. Animal Behavior, 55, 69-77. doi:10.1006/anbe.1997.0577

[12] Lohmann, K. and Lohmann, C. (1994) Acquisition of magnetic directional preference in hatchlings loggerhead sea turtles. Journal of Experimental Biology, 190, 1-8. 